\title{
Intubation during a medevac flight: safety and effect on total prehospital time in the helicopter emergency medical service system
}

Hiroki Maeyama ${ }^{1,2}$, Hiromichi Naito ${ }^{1 *}$ (D), Francis X. Guyette ${ }^{3}$, Takashi Yorifuji ${ }^{4}$, Yuki Banshotani ${ }^{5}$, Daisaku Matsui ${ }^{5}$, Tetsuya Yumoto ${ }^{1}$, Atsunori Nakao ${ }^{1}$ and Makoto Kobayashi ${ }^{5}$

\begin{abstract}
Introduction: The Helicopter Emergency Medical Service (HEMS) commonly intubates patients who require advanced airway support prior to takeoff. In-flight intubation (IFI) is avoided because it is considered difficult due to limited space, difficulty communicating, and vibration in flight. However, IFI may shorten the total prehospital time. We tested whether IFI can be performed safely by the HEMS.

Methods: We conducted a retrospective cohort study in adult patients transported from 2010 to 2017 who received prehospital, non-emergent intubation from a single HEMS. We divided the cohort in two groups, patients intubated during flight (flight group, FG) and patients intubated before takeoff (ground group, GG). The primary outcome was the proportion of successful intubations. Secondary outcomes included total prehospital time and the incidence of complications.

Results: We analyzed 376 patients transported during the study period, 192 patients in the FG and 184 patients in the GG. The intubation success rate did not differ between the two groups (FG 189/192 [98.4\%] vs. GG 179/184 [97.3\%], $p=0.50$ ). There were also no differences in hypoxia (FG 4/117 [3.4\%] vs. GG 4/95 [4.2\%], $p=1.00$ ) or hypotension (FG 6/117 [5.1\%] vs. GG 5/95 [5.3\%], $p=1.00$ ) between the two groups. Scene time and total prehospital time were shorter in the FG (scene time $7 \mathrm{~min}$ vs. $14 \mathrm{~min}, p<0.001$; total prehospital time 33.5 min vs. $40.0 \mathrm{~min}, p<0.001$ ).

Conclusions: IFI was safely performed with high success rates, similar to intubation on the ground, without increasing the risk of hypoxia or hypotension. IFI by experienced providers shortened transportation time, which may improve patient outcomes.
\end{abstract}

Keywords: Transportation, Airway management, Air ambulance, Time-to-treatment

\footnotetext{
* Correspondence: naito.hiromichi@gmail.com

'Department of Emergency, Critical Care, and Disaster Medicine, Okayama

University Graduate School of Medicine, Dentistry and Pharmaceutical

Sciences, 2-5-1 Shikata, Okayama 700-8558, Japan

Full list of author information is available at the end of the article
}

(c) The Author(s). 2020 Open Access This article is licensed under a Creative Commons Attribution 4.0 International License, which permits use, sharing, adaptation, distribution and reproduction in any medium or format, as long as you give appropriate credit to the original author(s) and the source, provide a link to the Creative Commons licence, and indicate if changes were made. The images or other third party material in this article are included in the article's Creative Commons licence, unless indicated otherwise in a credit line to the material. If material is not included in the article's Creative Commons licence and your intended use is not permitted by statutory regulation or exceeds the permitted use, you will need to obtain permission directly from the copyright holder. To view a copy of this licence, visit http://creativecommons.org/licenses/by/4.0/. The Creative Commons Public Domain Dedication waiver (http://creativecommons.org/publicdomain/zero/1.0/) applies to the data made available in this article, unless otherwise stated in a credit line to the data. 


\section{Background}

The Helicopter Emergency Medical Service (HEMS) typically intubates patients who need advanced airway management prior to takeoff. In-flight intubation (IFI) is often avoided because it is considered difficult due to limited space, difficulty communicating, and vibrations and gravitational forces in flight [1]. Endotracheal intubation (ETI) is a multistep process that includes preoxygenation, endotracheal tube preparation, establishing intravenous access, and administration of induction medications [2]. Moreover, it takes more time to complete ETI and secure both the endotracheal tube and the patient during emergency care. Intubation prior to takeoff may increase the total prehospital time. IFI may shorten the total prehospital time, as the procedure is conducted during the flight, and in some patients, this time difference may alter outcomes [3].

IFI has been described in only a few reports. Harrison and colleagues found no difference in HEMS IFI success rates as compared with ETI in the field and in-hospital ETI. Paramedic flight crews completed ETI with a success rate of 96.4\% [4]. Thomas and colleagues analyzed flight crew airway management in four different settings (in flight, at the trauma scene, in ambulances, and at hospitals) and found that airway management success rates were comparable, even in the in-flight setting [5]. However, the rate of complications associated with IFI has not been reported. Moreover, the prehospital time typical for IFI has not been described. We tested whether IFI can be successfully performed without increases in complications and whether IFI shortens total prehospital time as compared with intubation on the ground.

\section{Methods}

We performed a single-center, retrospective, cohort study. Patients were treated from April 1, 2010 to March 31, 2017 by the Toyooka Hospital HEMS, and data were obtained from hospital medical charts. The Toyooka Hospital Ethical Committee approved the study. The requirement for informed consent was waived. Study results are presented according to the STROBE guidelines for observational studies.

\section{HEMS system}

In the Japanese HEMS system, each base tertiary medical center employs one helicopter. Typically, the HEMS system receives a dispatch request from a ground Emergency Medical Service (EMS); then, a HEMS helicopter takes off from the hospital and lands at a predefined rendezvous point (RP). At the RP, the HEMS staff contacts the ground ambulance crew, stabilizes the patient, then transports the patient to the hospital. If the HEMS team reaches the RP before ground EMS, the HEMS staff may move from the RP to the scene to reach the patient (Fig. 1).

\section{Service area and protocol of Toyooka HEMS system}

The Toyooka HEMS system is responsible for the northern region of Hyogo Prefecture, the northern region of Kyoto Prefecture, and the eastern region of Tottori Prefecture, covering an area of approximately $6226 \mathrm{~km}^{2}$

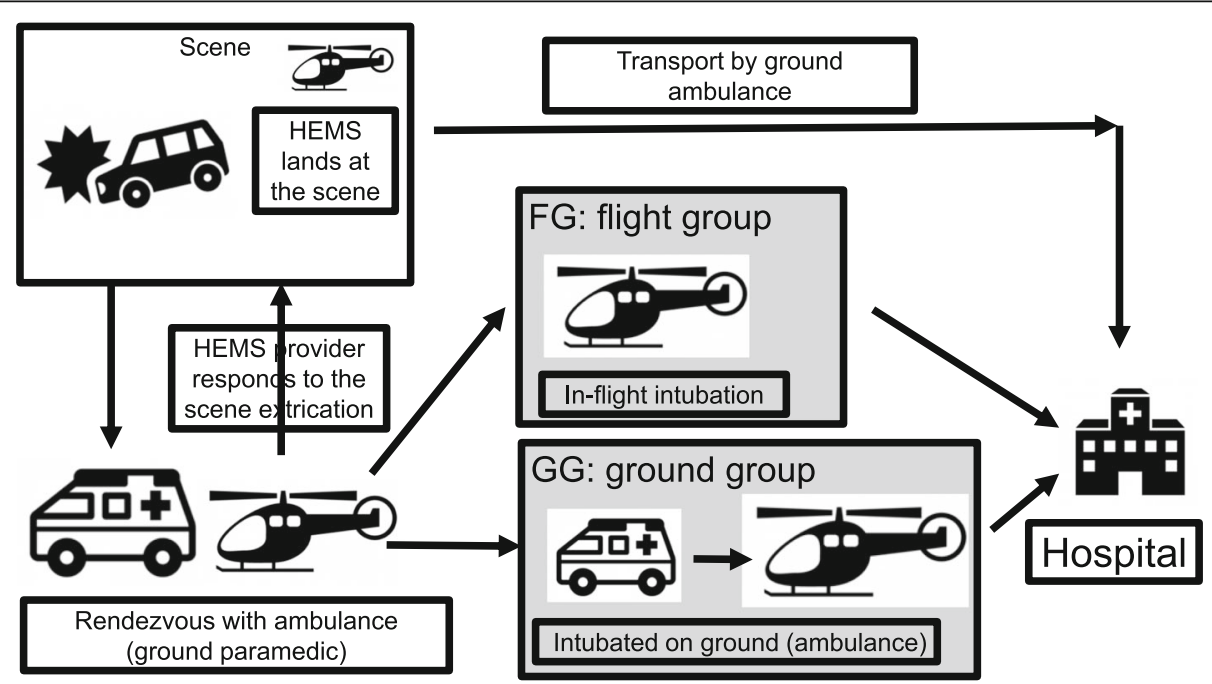

Fig. 1 Patient flow chart and grouping. Patients in the study were separated into 2 groups. Flight group (FG) patients were intubated during the flight; ground group (GG) patients were intubated on the ground prior to takeoff. The HEMS system receives a dispatch request from a public EMS, then takes off from the hospital and lands at the rendezvous point (RP). In some cases, the HEMS lands at the scene. Generally, at the RP, the HEMS staff make contact with the patient transported by the ground ambulance, treat the patient, then transport the patient to the hospital. If the HEMS team reaches the RP before ground EMS, the HEMS staff may respond to the scene. EMS: emergency medical service, HEMS: helicopter emergency medical service 
with a population of approximately 784,000 people. This area is rural and mountainous with only a few hospitals. The EC135 helicopter used by the Toyooka HEMS accommodates a maximum of seven passengers. Commonly, six passengers-a pilot, a mechanic, two physicians, a nurse, and the patient-are on board (Fig. 2). The HEMS physicians are thoroughly trained in airway management and ETI in the emergency department, intensive care unit, and operating room prior to assignment to the HEMS. Their training also includes ETI using a simulator for both video and direct laryngoscopy on the helicopter.

Most severe cases are treated by the HEMS system including patients with stroke, cardiovascular disease, sepsis, trauma, or cardiac arrest. ETI is performed for airway obstruction, regurgitation, respiratory failure (< percutaneous oxygen saturation $\left.\left[\mathrm{SpO}_{2}\right] 90 \%\right)$, circulatory failure (< systolic blood pressure [sBP] $90 \mathrm{mmHg}$ ), and coma (Glasgow Coma Scale score $<8$ ). Patients are intubated using sedatives (midazolam or ketamine), analgesics (fentanyl), and neuromuscular blockade (rocuronium or vecuronium). Rapid sequence induction was applied in most patients. The Pentax Airway Scope (AWS-S100; Pentax Corporation, Tokyo, Japan) was used for video laryngoscopy. The attending physician could freely choose to use either direct laryngoscopy or video laryngoscopy.

\section{Patient selection and data collection}

Patients over 18 years of age who were intubated by a Toyooka HEMS physician in the prehospital setting were included in this analysis. Exclusion criteria were interfacility transport, ground transport, declaration of death at the scene, and not transported by HEMS helicopter. We also excluded patients in whom total prehospital time was confounded by long extrication times or other procedures (Fig. 3).

Successful ETI attempts were verified by auscultation and end tidal carbon dioxide measurement. We divided patients into two groups for analysis. In the flight group (FG), patients were intubated after takeoff during the flight. In the ground group (GG), patients were intubated on the ground prior to takeoff, usually in the ambulance at the RP (Fig. 1).

The following measured data was collected: age, sex, etiology (medical conditions / "trauma and others"). Medical conditions included heart disease, respiratory disease, stroke, and sepsis. The classification "trauma and others" included trauma and suffocation. For the ETI procedure, we recorded success rate, number of

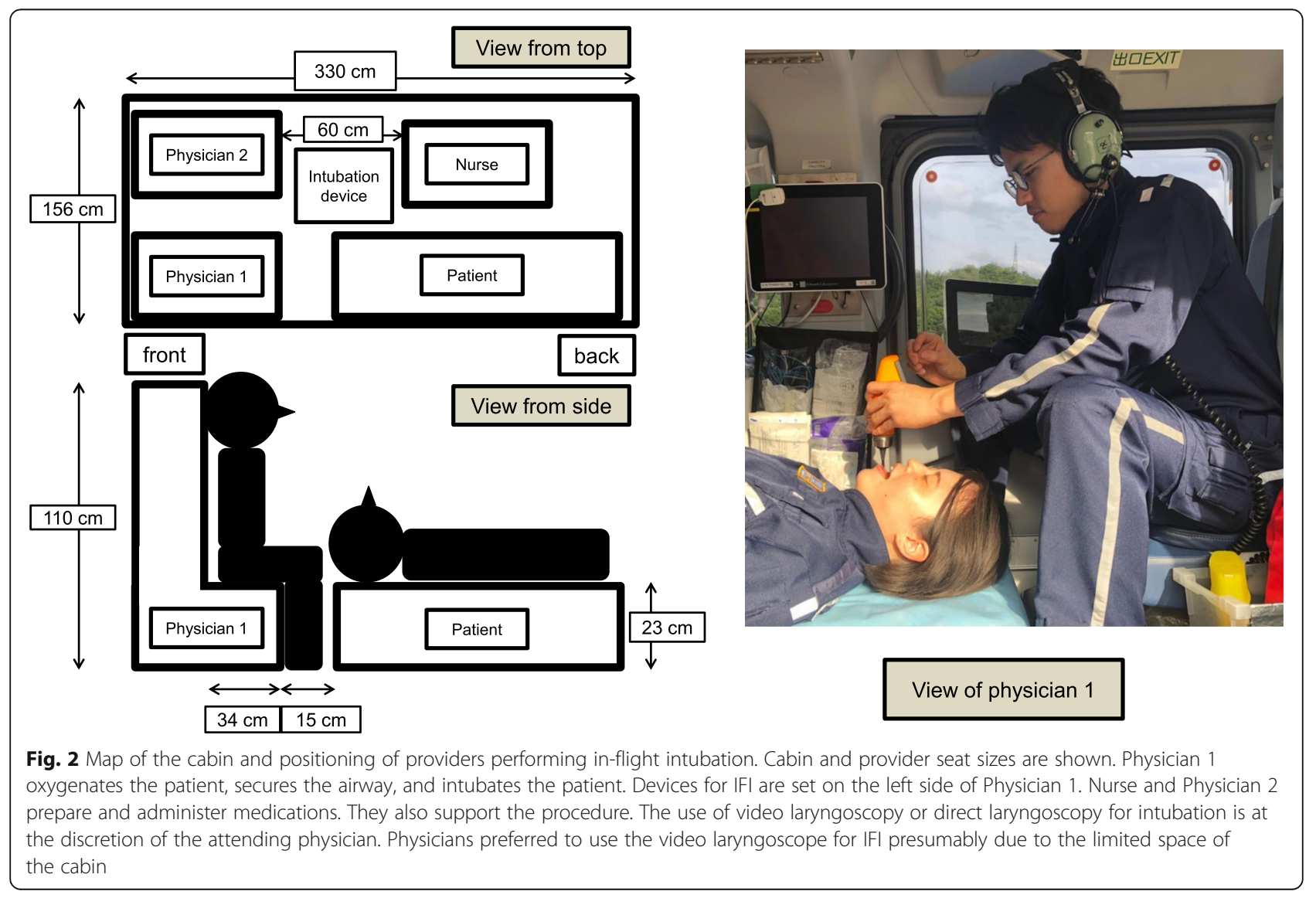




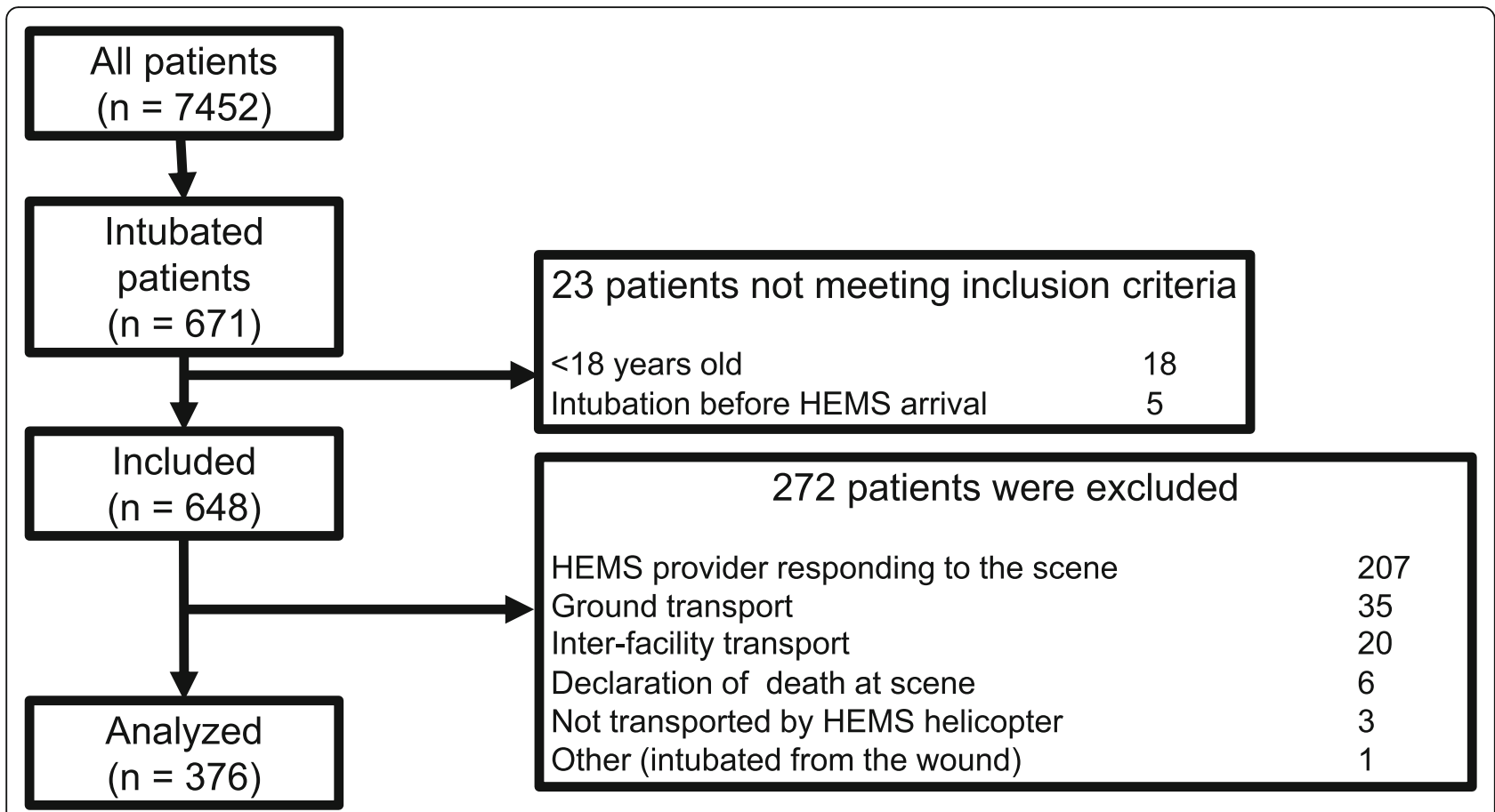

Fig. 3 STROBE diagram detailing the inclusion and exclusion criteria

attempts, use of video laryngoscopy or direct laryngoscopy, training of the emergency physician who performed the intubation, and whether the patient experienced hypoxia or hypotension during intubation. We recorded scene time (time from HEMS staff arrival at the RP to patient loading onto the helicopter) and total prehospital time (time from when the helicopter left the base hospital to when it arrived with the patient at the destination hospital). We defined hypoxia as the patient's $\mathrm{SpO}_{2}$ dropping below 90\% and hypotension as sBP below $90 \mathrm{mmHg}$ during intubation [6-9]. The primary outcome was the proportion of successful ETI. Secondary outcomes included scene time, total prehospital time, and incidence of hypoxia or hypotension.

\section{Data analysis}

Continuous variables were described as medians with interquartile range and compared using the MannWhitney U-test. Categorical variables were described as numbers or percentages and compared using Fisher's exact test. All statistical analyses were performed with EZR version 1.40 (Saitama Medical Center, Jichi Medical University; http://www.jichi.ac.jp/saitama-sct/SaitamaHP. files/statmed.html; Kanda, 2012), which is a graphical user interface for R (The R Foundation for Statistical Computing, Vienna, Austria, version 2.13.0) that was modified from $\mathrm{R}$ commander (version 1.6-3) to add functions frequently used in biostatistics [10]. All $p$-values were two sided, and $p<0.05$ was considered statistically significant.

\section{Results}

Of the 7452 patients treated by Toyooka HEMS during the study period, 671 were intubated. We excluded 295 patients who met the exclusion criteria (Fig. 3). Finally, 376 patients with a median age of 74 years (IQR 60-82) were analyzed. Of the 376 patients, 192 (51.1\%) were intubated in flight (FG) and 184 (48.9\%) were intubated prior to takeoff (GG) (Fig. 3). The groups did not differ with respect to age, sex, injury type, and vital signs at the scene (Table 1). However, the more patients in the GG had respiratory disease than in the FG ( $6 \%$ vs. $1.6 \%, p=0.03)$.

\section{ETI success rate, complications, and mortality}

The overall intubation success rate was not different between two groups (FG 189/192 [98.4\%] vs. GG 179/184 [97.3\%], $p=0.50$ ). First-pass success rate tended to be higher in the GG, but the difference was not significant (FG $88.5 \%$ vs. $93.5 \%, p=0.11$ ) (Table 2). There were five cases of failed intubation requiring cricothyrotomy, 1 in the FG and 4 in the GG, and bag-valve-mask ventilation was performed in 2 patients in the FG and one patient in the GG. There were no differences in the experience of the emergency services physician (FG 4.0 years vs. GG 4.0 years, $p=0.38$ ) or in the physicians' accumulated ETI experience between the groups (Table 2). Video laryngoscopy was used significantly more frequently in the FG 
Table 1 Patient characteristics for the two groups

\begin{tabular}{|c|c|c|c|}
\hline & $\begin{array}{l}\text { Flight Group } \\
(n=192)\end{array}$ & $\begin{array}{l}\text { Ground Group } \\
(n=184)\end{array}$ & $p$-value \\
\hline Age, median (IQR), y & $74(60-82)$ & $73(59-83)$ & 0.91 \\
\hline Male, No. (\%) & $135(70.3)$ & $115(62.5)$ & 0.13 \\
\hline Medical conditions, No. (\%) & $108(56.3)$ & $105(57.1)$ & 0.92 \\
\hline Heart disease & $45(23.4)$ & $40(21.7)$ & 0.71 \\
\hline Respiratory disease & $3(1.6)$ & $11(6.0)$ & 0.03 \\
\hline Stroke & $35(18.2)$ & $37(20.1)$ & 0.70 \\
\hline Sepsis & $2(1.0)$ & $0(0)$ & 0.50 \\
\hline Others & $23(12.0)$ & $17(9.2)$ & 0.41 \\
\hline Trauma and others, No. (\%) & $84(43.7)$ & 79 (42.9) & 0.92 \\
\hline Trauma & $55(28.6)$ & $48(26.1)$ & 0.64 \\
\hline Suffocation & $11(5.7)$ & $5(2.7)$ & 0.20 \\
\hline Others & $18(9.4)$ & $26(14.1)$ & 0.20 \\
\hline \multicolumn{4}{|l|}{ Vital sign, median $(\mathrm{IQR})^{\mathrm{a}}$} \\
\hline Respiratory rate & $22(18-30)$ & $22(16-28)$ & 0.56 \\
\hline Heart rate & $100(80-126)$ & $89(70-120)$ & 0.08 \\
\hline Systolic blood pressure & $130(80-180)$ & 129 (83-189) & 0.80 \\
\hline Glasgow Coma Scale & $6(3-11)$ & $6(3-7)$ & 0.19 \\
\hline CA, №. (\%) & $75(39.1)$ & $89(48.4)$ & 0.08 \\
\hline
\end{tabular}

Abbreviations: CA Cardiac arrest, IQR Inter quartile range aexcluding cardiac arrest than in the GG (FG 160/192 [83.3\%] vs. GG 35/184 [19.0\%], $p<0.001)$. In patients who were not experiencing cardiac arrest, there were no differences in the incidence of hypoxia or hypertension between the 2 groups (Table $2)$. Mortality was significantly higher in the GG (109/184, $64.5 \%)$ than in the FG $(86 / 192,45.7 \% ; p=0.01)$.

\section{Time elapsed prior to hospital arrival}

Finally, we examined whether IFI would affect how quickly the patient could be treated at the hospital. There was no difference in time from hospital takeoff to RP arrival between the 2 groups (FG 13 min vs. GG 13 min, $p=0.43)$. Scene time was approximately $7 \mathrm{~min}$ shorter in the FG (FG 7 min vs. GG $14 \mathrm{~min}, p<0.001$ ). Total prehospital time was also shorter for the FG (FG 33.5 min vs. GG $40.0 \mathrm{~min}, p<0.001$ ) (Table 3 ).

\section{Discussion}

This is the first report to describe the safety of IFI in the context of associated complications (hypoxia and hypotension) and the impact of IFI on total prehospital time. The success rate for intubation in the helicopter was high (98.4\%) and was similar to the success rates of prehospital ETI by physicians reported in other studies. (Table 4) [7, 11-14]. Additionally the overall ETI success rate did not differ between the FG and GG. Moreover, the incidences of hypoxia and hypotension were similar between the groups and consistent with previously published complication rates $[7,11,13,15]$. Our data indicate that ETI can be safely conducted by experienced providers during flight.

Table 2 ETI success rate, characteristics, complications, and death

\begin{tabular}{|c|c|c|c|}
\hline & Flight Group & Ground Group & $p$-value \\
\hline Successful cases, No. (\%) & 189/192 (98.4) & 179/184 (97.3) & 0.50 \\
\hline \multicolumn{4}{|l|}{ Number of ETI attempts, No. (\%) } \\
\hline First pass & 170/192 (88.5) & 172/184 (93.5) & 0.11 \\
\hline Second pass & 189/192 (98.4) & 178/184 (96.7) & 0.33 \\
\hline Third pass & & 179/184 (97.3) & \\
\hline Video laryngoscopy, No. (\%) & 160/192 (83.3) & $35 / 184(19.0)$ & $<0.001$ \\
\hline Cricothyroidotomy, No. (\%) & $1 / 192(0.5)$ & $4 / 184(2.2)$ & 0.21 \\
\hline Physician years specializing in emergency services, median (IQR), years & $4(3-6)$ & $4(3-5)$ & 0.38 \\
\hline \multicolumn{4}{|l|}{ Physician accumulated experience with intubations, No. (\%) } \\
\hline$>1000$ & $79(41)$ & $82(45)$ & 0.53 \\
\hline $501-1000$ & $35(18)$ & $36(20)$ & 0.79 \\
\hline $101-500$ & $78(41)$ & $66(36)$ & 0.40 \\
\hline \multicolumn{4}{|l|}{ Complications, excluding CA cases, No. (\%) } \\
\hline Hypoxia & 4/117 (3.4) & 4/95 (4.2) & 1.00 \\
\hline Hypotension & $6 / 117(5.1)$ & $5 / 95(5.3)$ & 1.00 \\
\hline Deaths, No. (\%) & $86 / 192(45.7)$ & 109/184 (64.5) & 0.01 \\
\hline
\end{tabular}

ETI Endotracheal intubation, CA Cardiac arrest, IQR Interquartile range 
Table 3 Prehospital time

\begin{tabular}{llll}
\hline & $\begin{array}{l}\text { Flight Group } \\
(\boldsymbol{n}=\mathbf{1 9 2})\end{array}$ & $\begin{array}{l}\text { Ground Group } \\
(\boldsymbol{n}=\mathbf{1 8 4})\end{array}$ & $\boldsymbol{p}$-value \\
\hline Takeoff to RP arrival, median (IQR), min & $13(10-16)$ & $13(9-17)$ & 0.43 \\
Prehospital activity time, median (IQR), min & $7(5-9)$ & $14(11-17)$ & $<0.001$ \\
Total prehospital time, median (IQR), min & $33.5(28-40)$ & $40(33-47)$ & $<0.001$ \\
\hline
\end{tabular}

Abbreviations: $R P$ Rendezvous point, $I Q R$ Interquartile range

Mortality is reduced almost $50 \%$ by treating patients in the field as compared with patients treated later in a trauma center [16]. However, prehospital ETI may prolong prehospital time by $12 \mathrm{~min}$, leading to a delay in definitive care [17]. Lansom and colleagues reported that prehospital intubation prolonged total prehospital time by $25 \mathrm{~min}$, but shortened the time from arrival at the emergency department to the initiation of computed tomography imaging by $11 \mathrm{~min}$ [18]. In patients with heart disease, mortality was decreased to an adjusted odds ratio of $0.49-0.73$ when total prehospital time was shortened [19]. Trauma mortality is decreased by shortening the scene time to $<50 \%$ of the total prehospital time [20]. In our study, intubating patients in the helicopter decreased scene time by $7 \mathrm{~min}$. Similarly, Nakstad and colleagues reported that the scene time was prolonged by approximately 8 min when ETI was performed [21]. Additionally, when patients arrive intubated to the emergency department, it may facilitate critical examinations or interventions. Further research is needed to determine if the 7min shortening that we observed decreases mortality.

In the current study, approximately half of patients were intubated using video laryngoscopy, with a significantly larger proportion in the FG. Past studies describing IFI were conducted in the 1990s before the widespread adoption of the video laryngoscope $[4,5]$, and therefore, did not address the use of the device. During flight, the distance between the physician performing ETI and the head of patient is approximately $15 \mathrm{~cm}$. The fixed low position of the stretcher and the position of the physician's knee near the patient's head may make ETI using direct laryngoscopy difficult. Video laryngoscopy may have provided the HEMS physicians with an improved laryngoscopic view and contributed to the observed high success rates. Additionally, in the helicopter, video laryngoscopy allows providers to share their view and may have improved communication with the assisting providers, which is typically limited to communication through headsets given the noisy environment. Finally, the ergonomics and thicker blade of the video laryngoscope may have improved the intubation conditions, given the vibration in the aircraft. Because it is difficult to confirm ETI by auscultation in flight, the ability of the video laryngoscopy to provide capnography and direct visualization facilitates safe confirmation of airway management after takeoff.

Intubation success generally depends on the experience of the provider [22, 23]. ETI success rates are higher when a physician performs the procedure as compared with paramedics or nurse providers [24-26], which may partly explain the high IFI success rate we observed. However, 2 prior studies of IFI with experienced paramedics performing the procedure had success rates

Table 4 Comparative data of prehospital intubation by physician from the present and previous studies

\begin{tabular}{|c|c|c|c|c|c|c|}
\hline & $\begin{array}{l}\text { Helm M, et al. } \\
\text { [7] (2013) }\end{array}$ & $\begin{array}{l}\text { Sunde GA, } \\
\text { et al. [11] (2015) }\end{array}$ & $\begin{array}{l}\text { Piegeler T, et al. } \\
\text { [12] (2016) }\end{array}$ & $\begin{array}{l}\text { Caruana E, et al. } \\
\text { [13] (2015) }\end{array}$ & $\begin{array}{l}\text { Kamiutsuri K, } \\
\text { et al. [14] (2013) }\end{array}$ & $\begin{array}{l}\text { This study } \\
(2020)\end{array}$ \\
\hline Number & 150 & 2144 & 988 & 1251 & 742 & 376 \\
\hline \multirow[t]{2}{*}{ Age, y } & \multirow[t]{2}{*}{$40(21-61)^{a}$} & \multirow[t]{2}{*}{$53(0-95)^{a}$} & $49.7(25.7-65.9)^{a} b$ & \multirow[t]{2}{*}{$60.3(18.6)^{d}$} & CA $61.8(20.9)^{d}$ & \multirow[t]{2}{*}{$74(60-82)^{e}$} \\
\hline & & & $52.7(34.5-66.5)^{\mathrm{ac}}$ & & Non CA $50.7(20.4)^{d}$ & \\
\hline Medical (\%) & 22.0 & 55.0 & NA & NA & $68 \%(C A), 13.6 \%$ (Non-CA) & 56.4 \\
\hline Trauma (\%) & 78.0 & 44.0 & NA & NA & $32 \%(C A), 86.4 \%$ (Non-CA) & 27.7 \\
\hline CA (\%) & 0.0 & 42.0 & 46.4 & 57.4 & 61.3 & 44.0 \\
\hline \multicolumn{7}{|l|}{ Success rate (\%) } \\
\hline Total & 100.0 & 98.7 & 99.5 & 99.5 & 99.1 & 97.9 \\
\hline First pass & 92.0 & 85.5 & 96.4 & 63.8 & NA & 91.8 \\
\hline Second or additional passes & 8.0 & 13.2 & 3.1 & 35.7 & NA & 7.7 \\
\hline Hypoxia, excluding CA (\%) & 12.0 & 2.1 & NA & 10.0 & NA & 3.7 \\
\hline Hypotension, excluding CA (\%) & NA & 3.0 & NA & 1.3 & NA & 5.2 \\
\hline
\end{tabular}


Table 5 Comparative data of in-flight intubation from the present and previous studies

\begin{tabular}{llll}
\hline & Harrison T, et al. [4] (1997) & Thomas SH, et al. [5] (1999) & This study (flight group) (2020) \\
\hline Number & 120 & 246 & 192 \\
Age, y & $27(2-75)^{\mathrm{a}}$ & NA & $74(60-82)^{\mathrm{b}}$ \\
Medical (\%) & 23.0 & NA & 56.3 \\
Trauma (\%) & 77.0 & NA & 28.6 \\
CA (\%) & 42.0 & NA & 39.1 \\
Success rate (\%) & & & 98.4 \\
$\quad$ Total & 94.2 & 95.5 & 88.5 \\
$\quad$ First attempt & 75.0 & 71.9 & 9.9 \\
$\quad$ Two or more attempts & 19.2 & 23.6 & 3.4 \\
Hypoxia, excluding CA (\%) & NA & NA & 5.1 \\
Hypotension, excluding CA (\%) & NA & NA & \\
\hline
\end{tabular}

Abbreviations: CA Cardiac arrest, IQR Interquartile range. ${ }^{\mathrm{a}}$ median (range) ${ }^{\mathrm{b}}$ median (IQR)

exceeding 95\%, indicating the feasibility of IFI by other experienced providers (Table 5). Because the incidence of hypoxia and hypotension in our study did not differ from that seen previously, our findings support that safety will be maintained when intubation is performed by an experienced provider $[7,11,13]$. The providers' experience and the air medical education programs available should be carefully considered before the introduction of IFI in a HEMS system. Moreover, patient selection should be limited to patients with time-dependent conditions that justify intubation in the aircraft. We believe that adapting IFI to flight crews with different provider compositions will require further study and verification.

Our investigation has several limitations. The study was performed using data from a single HEMS with ETI performed only by highly trained physicians; therefore, the results may not be generalizable to other EMSs. We could not obtain intubation times for these patients; however, scene time may be a surrogate for estimating procedure time. We did not adjust for patient mortality between the groups due to the diversity of patients and the retrospective nature of the study. Patients with more severe conditions may have been intubated before flight more frequently, which may explain why the proportion of patients with cardiac arrest or respiratory disease was higher in the GG. Finally, we could not examine whether the decreased prehospital time afforded by IFI in this study translated into improved outcomes.

\section{Conclusions}

IFI was safely performed with high success rates, similar to intubation on the ground, without increasing the risk of hypoxia or hypotension. IFI by experienced providers decreased total prehospital time. Further studies are needed to determine if this strategy is associated with improved patient outcomes.

\section{Abbreviations}

EMS: Emergency Medical Service; ETI: Endotracheal intubation; FG: Flight group; GG: Ground group; HEMS: Helicopter Emergency Medical Service; IFI: In-flight intubation; sBP: Systolic blood pressure; SpO2: Percutaneous oxygen saturation; RP: Rendezvous point

\section{Acknowledgements}

The authors thank Christine Burr and Shannon Wyszomierski for editing the manuscript.

\section{Authors' contributions}

HM planed this retrospective study, analyzed data, and drafted the manuscript. HN participated in designing this study, analyzing data, and revising the manuscript. FXG participated in designing this study, analyzing data, and revising the manuscript. TY participated in designing this study, analyzing data, and revising the manuscript. YB participated in designing this study, collecting data, and revising the manuscript. DM participated in designing this study, collecting data, and revising the manuscript. TY participated in designing this study, analyzing data, and revising the manuscript. AN participated in designing this study, analyzing data, and revising the manuscript. MK participated in designing this study, collecting data, and revising the manuscript. All authors read and approved the final manuscript.

\section{Funding}

The authors received no financial support for the research, authorship, and/ or publication of this article.

\section{Availability of data and materials}

Data was available upon reasonable request.

\section{Ethics approval and consent to participate}

The study was performed according to the Helsinki Declaration and Toyooka Hospital review board approval was duly obtained (registration number, 137).

Consent for publication

Consent for publication was waived.

\section{Competing interests}

The authors declared no potential conflicts of interest with respect to the research, authorship, and/or publication of this article.

\section{Author details}

'Department of Emergency, Critical Care, and Disaster Medicine, Okayama University Graduate School of Medicine, Dentistry and Pharmaceutical Sciences, 2-5-1 Shikata, Okayama 700-8558, Japan. ${ }^{2}$ Department of Emergency and Critical Care Medicine, Tsuyama Chuo Hospital, Tsuyama, Japan. ${ }^{3}$ Department of Emergency Medicine, University of Pittsburgh School 
of Medicine, Pittsburgh, PA, USA. ${ }^{4}$ Department of Epidemiology, Okayama University Graduate School of Medicine Dentistry and Pharmaceutical Sciences, Okayama, Japan. ${ }^{5}$ Tajima Emergency and Critical Care Medical Center, Toyooka Public Hospital, Toyooka, Japan.

Received: 20 January 2020 Accepted: 1 September 2020

Published online: 07 September 2020

\section{References}

1. Andrew N. Critical care transport. In: Mike M, Jeffrey SR, Michael M, editors Jones \& Bartlett Learning. 2nd ed; 2017.

2. Hossfeld B, Bein B, Boettiger BW, Bohn A, Fischer M, Graesner JT, et al. Recommended practice for out-of-hospital emergency anaesthesia in adults: statement from the out-of-hospital emergency Anaesthesia working Group of the Emergency Medicine Research Group of the German Society of Anaesthesiology and Intensive Care. Eur J Anaesthesiol. 2016;33:881-97.

3. Newgard CD, Meier EN, Bulger EM, Buick J, Sheehan K, Lin S, et al. Revisiting the "Golden Hour": An Evaluation of Out-of-Hospital Time in Shock and Traumatic Brain Injury. Ann Emerg Med. 2015;66:30-41, 41.e1-3. American College of Emergency Physicians. Available from. https://doi.org/10.1016/j. annemergmed.2014.12.004.

4. Harrison T, Thomas SH, Wedel SK. In-flight oral endotracheal intubation. Am J Emerg Med. 1997;15:558-61.

5. Thomas SH, Harrison T, Wedel SK. Flight crew airway management in four settings: A six-year review. Prehospital Emerg Care. 1999;3:310-5.

6. Newton A, Ratchford A, Khan I. Incidence of adverse events during prehospital rapid sequence intubation: a review of one year on the London helicopter emergency medical service. J Trauma - Inj Infect Crit Care. 2008; 64:487-92.

7. Helm M, Kremers G, Lampl L, Hossfeld B. Incidence of transient hypoxia during pre-hospital rapid sequence intubation by anaesthesiologists. Acta Anaesthesiol Scand. 2013;57:199-205.

8. Sunde GA, Sandberg M, Lyon R, Fredriksen K, Burns B, Hufthammer KO, et al. Hypoxia and hypotension in patients intubated by physician staffed helicopter emergency medical services - a prospective observational multicentre study. BMC Emerg Med. 2017;17:22 Available from: http:// bmcemergmed.biomedcentral.com/articles/10.1186/s12873-017-0134-5.

9. Wimalasena $\mathrm{YH}$, Corfield AR, Hearns S. Comparison of factors associated with desaturation in prehospital emergency anaesthesia in primary and secondary retrievals. Emerg Med J. 2015;32:642-6 Available from: http://emj. bmj.com/lookup/doi/10.1136/emermed-2013-202928.

10. Kanda Y. Investigation of the freely available easy-to-use software "EZR" for medical statistics. Bone Marrow Transplant. 2013:48:452-8.

11. Sunde GA, Heltne J-K, Lockey D, Burns B, Sandberg M, Fredriksen K, et al. Airway management by physician-staffed Helicopter Emergency Medical Services - a prospective, multicentre, observational study of 2,327 patients. Scand J Trauma Resusc Emerg Med. 2015;23:57 Available from: http://www. sjtrem.com/content/23/1/57.

12. Piegeler $T$, Neth $P$, Schlaepfer M, Sulser $S$, Albrecht $R$, Seifert B, et al. Advanced airway management in an anaesthesiologist-staffed helicopter emergency medical service (HEMS): a retrospective analysis of 1047 out-ofhospital intubations. Resuscitation. 2016;105:66-9 Available from: http:// www.ncbi.nlm.nih.gov/pubmed/27241333.

13. Caruana E, Duchateau FX, Cornaglia C, Devaud ML, Pirracchio R. Tracheal intubation related complications in the prehospital setting. Emerg Med J. 2015:32:882-7.

14. Kamiutsuri K, Okutani R, Kozawa S. Analysis of prehospital endotracheal intubation performed by emergency physicians: retrospective survey of a single emergency medical center in Japan. J Anesth. 2013;27:374-9 Available from: http://www.ncbi.nlm.nih.gov/pubmed/23238811.

15. Nakstad AR, Heimdal H-J, Strand T, Sandberg M. Incidence of desaturation during prehospital rapid sequence intubation in a physician-based helicopter emergency service. Am J Emerg Med. 2011;29:639-44 Available from: http://www.ncbi.nlm.nih.gov/pubmed/20825848.

16. Gomes E, Araújo R, Carneiro A, Dias C, Costa-Pereira A, Lecky FE. The importance of pre-trauma Centre treatment of life-threatening events on the mortality of patients transferred with severe trauma. Resuscitation. 2010; 81:440-5.

17. Sollid SJM, Lossius HM, Søreide E. Pre-hospital intubation by anaesthesiologists in patients with severe trauma: an audit of a Norwegian helicopter emergency medical service. Scand J Trauma Resusc Emerg Med. 2010;18:1-6.

18. Lansom JD, Curtis K, Goldsmith H, Tzannes A. The effect of Prehospital intubation on treatment times in patients with suspected traumatic brain injury. Air Med J. 2016;35:295-300.

19. Mills EHA, Aasbjerg K, Hansen SM, Ringgren KB, Dahl M, Rasmussen BS, et al. Prehospital time and mortality in patients requiring a highest priority emergency medical response: a Danish registry-based cohort study. BMJ Open. 2019;9:e023049.

20. Brown JB, Rosengart MR, Forsythe RM, Reynolds BR, Gestring ML, Hallinan WM, et al. Not all prehospital time is equal. J Trauma Acute Care Surg. 2016; 81:93-100 Available from: http://content.wkhealth.com/linkback/ openurl?sid=WKPTLP:landingpage\&an=01586154-201607000-00015.

21. Nakstad AR, Strand T, Sandberg M. Landing sites and intubation may influence helicopter emergency medical services on-scene time. J Emerg Med. 2011;40:651-7 Available from: http://www.ncbi.nlm.nih.gov/pubmed/2 0739134.

22. Kim SY, Park SO, Kim JW, Sung J, Lee KR, Lee YH, et al. How much experience do rescuers require to achieve successful tracheal intubation during cardiopulmonary resuscitation? Theatr Res Int. 2018;133:187-92 Available from: https://linkinghub.elsevier.com/retrieve/pii/S0300957218308293.

23. Je S, Cho Y, Choi HJ, Kang B, Lim T, Kang H. An application of the learning curve-cumulative summation test to evaluate training for endotracheal intubation in emergency medicine. Emerg Med J. 2015;32:291-4 Available from: http://www.ncbi.nlm.nih.gov/pubmed/24154942.

24. Lossius HM, Røislien J, Lockey DJ. Patient safety in pre-hospital emergency tracheal intubation: a comprehensive meta-analysis of the intubation success rates of EMS providers. Crit Care. 2012;16:R24 Available from: http:// www.ncbi.nlm.nih.gov/pubmed/22325973.

25. Crewdson K, Lockey DJ, Røislien J, Lossius HM, Rehn M. The success of prehospital tracheal intubation by different pre-hospital providers: a systematic literature review and meta-analysis. Crit Care. 2017;21:31 Available from: http://www.ncbi.nlm.nih.gov/pubmed/28196506.

26. Peters J, van Wageningen B, Hendriks I, Eijk R, Edwards M, Hoogerwerf $N$, et al. First-pass intubation success rate during rapid sequence induction of prehospital anaesthesia by physicians versus paramedics. Eur J Emerg Med. 2015;22:391-4 Available from: http://www.ncbi.nlm.nih.gov/pubmed/24841771.

\section{Publisher's Note}

Springer Nature remains neutral with regard to jurisdictional claims in published maps and institutional affiliations.

Ready to submit your research? Choose BMC and benefit from:

- fast, convenient online submission

- thorough peer review by experienced researchers in your field

- rapid publication on acceptance

- support for research data, including large and complex data types

- gold Open Access which fosters wider collaboration and increased citations

- maximum visibility for your research: over $100 \mathrm{M}$ website views per year

At BMC, research is always in progress.

Learn more biomedcentral.com/submissions 